\title{
Singularidades da comunicação no encontro de pessoas surdas e profissionais de saúde mental
}

\section{| ${ }^{1}$ Bruna Romano, ${ }^{2}$ Octavio Domont de Serpa Jr |}

Resumo: Parte da luta dos movimentos das pessoas com deficiência tem sido, não apenas o reconhecimento da diversidade humana, mas a compreensão de que pessoas com a mesma deficiência, por exemplo a surdez, não são um grupo homogêneo. Os profissionais da saúde, diante dessa diversidade podem sentir-se despreparados e com conhecimentos insuficientes. O objetivo deste estudo é apresentar as diferentes formas de comunicação que podem acontecer quando surdos são atendidos em serviços de saúde mental, por meio de um Estudo de Casos Múltiplos. Os resultados apontam para a diversidade nas formas de comunicação, convocando os profissionais a criarem novas formas de trabalho e cuidado no encontro com surdos usuários dos serviços de saúde mental. É no cotidiano do trabalho, com cada usuário que as formas de cuidado singulares que levam em conta a diversidade ganham vida e para que isso aconteça, é importante incluir a diversidade na comunicação. A criação de formas de comunicação que incluam a diversidade e as necessidades singulares, somente serão possíveis com apoio aos profissionais de saúde através de espaços informativos e de educação permanente.

> Palavras-chave: Acesso; diversidade; surdez; saúde mental.
${ }^{1}$ Universidade Federal do Rio de Janeiro. Rio de Janeiro -RJ, Brasil (brunaromanogomes@gmail.com). ORCID: 0000-0002-2916-8443

2 Universidade Federal do Rio de Janeiro. Rio de Janeiro -RJ, Brasil (domserpa@gmail.com). ORCID: 0000-0001-6827-4057

Recebido em: 19/09/2019 Aprovado em: 12/01/2020 Revisado em: 19/05/2021 


\section{Introdução}

Apesar do reconhecimento das pessoas com deficiência como um grupo que possui necessidades específicas a serem atendidas no que diz respeito a acessibilidade, tem sido parte das lutas dos movimentos das pessoas com deficiência a defesa da diversidade humana e da ideia de que dentro de grupos aparentemente homogêneos, como os das pessoas com uma mesma deficiência, há grupos com desejos e necessidades de acessibilidade ${ }^{1}$ diferentes (TORRES, MAZONNI, MELLO, 2007).

Para pessoas surdas as necessidades de acessibilidade estão relacionadas, além da diferença sensorial - não ouvir - com diversos fatores: preferências individuais, acesso a serviços de reabilitação auditiva, acesso à escola bilíngue, contato com grupos e comunidades surdas, acesso a tecnologias, posicionamento político e suas experiências com relação a esses diversos fatores. A começar pelo nome (surdos ou pessoas com deficiência auditiva) as narrativas em torno da experiência dessa diferença sensorial são múltiplas e por vezes discordantes.

O objetivo deste trabalho é apresentar diferentes formas de comunicação que podem acontecer no encontro entre sujeitos surdos e profissionais de saúde nos serviços de saúde mental. Pretende-se destacar como pessoas sob a égide de uma mesma diferença sensorial podem desenvolver experiências distintas, exigindo respostas singulares de seu interlocutor. Para alcançar tal objetivo serão apresentados e discutidos três casos de pessoas surdas acompanhadas por serviços de saúde mental que apresentam diferentes formas de se comunicar e se relacionar. A escolha dos três casos deu-se considerando a diversidade de formas na comunicação, buscando demonstrar a diversidade existente com relação as necessidades de comunicação de pessoas surdas.

\section{Pessoas Surdas e Acesso a Serviços de Saúde}

O Modelo Médico toma a deficiência como um problema individual no corpo, que sofre intervenções no sentido de sua normalizaçáa ${ }^{2}$. No campo da Surdez, durante muito tempo, esse modelo tendia a tomar a língua de sinais como um desvio da normalidade e como algo que deveria ser combatido, buscando a integração do surdo com a superação da surdez, por meio da medicalização e inserção de padrôes culturais hegemônicos ouvintes, como a língua oral (MASCARENHAS, 2016). 
Na perspectiva do Modelo Social da deficiência, que faz oposição ao Modelo Médico, a deficiência é apresentada como um fenômeno que não está restrito ao corpo e sim "na produção social e cultural que define determinadas variações corporais como inferiores, incompletas ou passíveis de reparação/reabilitação quando situadas em relaçâo à corponormatividade” (MELLO, NUERNBERG, 2012, p. 636). Essa concepção busca elucidar as relaçôes de opressão e exclusão que não estão inscritas no corpo, mas nas formas como se concebe o corpo normal e consequentemente, o fora da normalidade. As intervençóes nos corpos deixam de ser necessárias, sendo mais importantes mudanças nas relaçôes e nas possibilidades de existência e circulação para os diversos corpos - corpo idoso, corpo surdo, corpo cego, etc.

Os Estudos Surdos buscam o reconhecimento de uma cultura compartilhada entre sujeitos surdos, "a experiência visual, a língua de sinais, as histórias de lutas por reconhecimento, a importância do encontro surdo-surdo, entre outros” (MARTINS, 2013, p.27). Ser surdo é pertencer a uma cultura que possui formas próprias de compreender e intervir no mundo, pertencer a um povo que tem uma língua, ideias, crenças, costumes e hábitos (STROBEL, 2016). Contrapóem-se também ao Modelo Médico e as ideias de normalização dos corpos, onde o corpo surdo é compreendido como um corpo em falta, portanto passível de intervençôes e correçôes, como reabilitação ou cirurgia de implante coclear. Nessa perspectiva, a surdez marca um modo de relacionar-se, negando a identidade de pessoa com deficiência, para afirmar cultura e língua como formas de existência e resistência à cultura dominante (ouvinte). Os autores dos Estudos Surdos, utilizam como matriz teórica os Estudos Culturais ${ }^{3}$, não convergindo necessariamente com o Modelo Social da Deficiência, pois não se identificam como pessoas com deficiência, colocando-se enquanto minoria cultural. Trata-se, portanto, de uma escolha teórica e política.

Diferentes concepçôes representam diferentes formas de lidar com a surdez e com a língua. Somada às trajetórias e experiências de vida de cada sujeito surdo compóese um universo de formas de se comunicar e relacionar. Variaçóes do momento em que ocorre a perda auditiva (antes ou depois do desenvolvimento da fala), dos recursos com os quais a pessoa conta (por exemplo, aparelho auditivo), das relaçóes que desenvolve ao longo da vida, da capacidade para fazer leitura labial, do nível de domínio do português oral e escrito, das escolhas pessoais, dos serviços a que teve acesso, complexificam a questão. 
Utilizando-se da matriz de experiência para discutir subjetividades surdas, Witchs e Lopes (2015) apontam a impossibilidade de descrever a surdez de maneira única e heterogênea. Os autores destacam dois modos, construídos historicamente a partir de como os surdos são vistos (seja por si ou pelos outros). "A ideia de ser surdo é contrária a ideia de ser deficiente auditivo. Enquanto a primeira é caracterizada como uma diferença cultural, a segunda está alojada no campo discursivo da medicina” (p.46).

Pensar o acesso de pessoas surdas a serviços de saúde pressupóe considerar os diferentes modos de experienciar a surdez e consequentemente, produz distintas demandas de acessibilidade. Por exemplo, se um surdo compreende a Língua Brasileira de Sinais (Libras) $)^{4}$ como parte de sua cultura e modo de existir, será fundamental ser atendido através dela. Já para um surdo que não tem essa compreensão ou não teve contato com a língua, fará pouco sentido ser atendido nela, necessitando de outas formas de comunicação.

Mello (s. d.) destaca a diversidade entre as pessoas surdas: surdos sinalizantes (utilizam língua de sinais como principal forma de comunicação), surdos oralizados (desenvolveram habilidades em língua oral), surdos implantados (usuários de implante coclear), surdos bilíngues (surdos com habilidades em Libras e português oral e/ou escrito) e os deficientes auditivos (aqueles cuja deficiência é corrigida pelo uso de Aparelho de Amplificação Sonora Individual (AASI), ensurdecidos (perderam a audição).

Evidencia-se, portanto, que as necessidades com relação à comunicação e acessibilidade das pessoas surdas não são homogêneas e negligenciar a diversidade existente pode levar a equívocos "refletidos inclusive em documentos legais, bem como a uma inadequada utilização de recursos humanos, financeiros e tecnológicos" (TORRES, MAZZONI, MELLO, 2007, p 374).

Quando se trata de buscar atendimento em serviços de saúde, pessoas surdas deparam-se com a existência de importantes barreiras no atendimento comprometendo a relação entre usuário e profissional de saúde e, consequentemente, a qualidade do serviço prestado (LOPES, VIANA, SILVA, 2017; FRANÇA et al, 2016; CHAVEIRO et al, 2010; COSTA et al, 2009; CHAVEIRO, BARBOSA e PORTO 2008; CARDOSO, RODRIGUES, BACHION, 2006; CHAVEIRO, BARBOSA, 2005; SANTOS, SHIRATORI, 2004). 
Os profissionais que já atenderam pessoas surdas apontam que a comunicação eficaz é um instrumento essencial e torna-se um grande desafio. A língua de sinais é compreendida como um recurso de comunicação que precisa ser melhor-entendido, reconhecendo também "seus aspectos suprassegmentais, que incluem gestos, expressões faciais e corporais”. A pesquisa aponta para uma lacuna na formação dos profissionais de saúde no que diz respeito ao atendimento de pessoas surdas, em especial se considerarmos que a maioria dos cursos de saúde aborda a surdez como uma condição patológica (CHAVEIRO et al, 2010, p. 624).

Os profissionais de saúde percebem que seus conhecimentos são insuficientes para atender e realizar o diagnóstico em pessoas surdas e apontam para a falta de treinamentos e recursos audiovisuais para auxiliar no contato com os surdos (FRANÇA et al, 2016). Além da educação continuada dos profissionais éfundamental a sensibilização e formação, ainda na graduação dos diversos profissionais da saúde para esta temática (COSTA, 2015).

Para que seja prestada uma assistência de qualidade nos serviços de saúde os processos de comunicação precisam ser abordados na formação dos profissionais de saúde (OLIVEIRA, CELINO, COSTA, 2015; TEDESCO, JUNGES, 2013; BARBOSA et al, 2003), não apenas a língua de sinais, mas também a concepção da comunicação com o surdo de maneira ampliada, contemplando estratégias de comunicação, aspectos da cultura surda, noçóes de Libras, leitura labial, e como se posicionar de maneira a facilitar a comunicação (CHAVEIRO, BARBOSA, PORTO, 2008).

Assim, a não homogeneidade da população surda, a necessidade de os serviços construírem estratégias de cuidado concordantes com as demandas que chegam, atreladas ainda às dificuldades dos profissionais devido a lacunas em sua formação constituem-se um enorme desafio para os serviços de saúde quando recebem uma pessoa surda.

\section{Métodos}

Este trabalho é o recorte de uma pesquisa de mestrado que teve como tema a investigação do acesso de pessoas surdas aos dispositivos de saúde mental e as formas de cuidado ofertadas a elas nesses dispositivos. Utilizou-se a metodologia qualitativa, pelo entendimento de que a pesquisa "qualitativa (...) trabalha com um universo de significados, motivos, aspiraçóes, crenças, valores e atitudes, o que corresponde a um espaço mais profundo das relaçóes, dos processos e dos fenômenos" (MINAYO, 2002). 
Dada a escassez de estudos anteriores e a especificidade da temática, optouse pelo Estudo de Caso, pois enquanto método de pesquisa contribui, de forma inigualável, para o entendimento de fenômenos individuais, organizacionais, sociais e políticos, sendo amplamente utilizado quando há a necessidade de compreender fenômenos sociais complexos. $\mathrm{O}$ estudo de caso possibilita uma investigação que preserva as características holísticas e significativas dos eventos da vida real, sendo de grande utilidade para a investigação inicial de temas complexos (YIN, 2001). Assim, o estudo de múltiplos casos possibilitou a investigação de um tema complexo, como o acesso de pessoas surdas a serviços de saúde mental, considerando o todo, bem como as características específicas de cada caso, fazendo emergir as diferentes formas como diferentes sujeitos podem se comunicar.

A escolha dos casos estudados é intencional, sendo o cenário de estudos os Centros de Atenção Psicossocial - CAPS da rede de serviços do Rio de Janeiro que acompanhavam usuários surdos por este ser um dispositivo chave na atual configuração dos serviços de saúde mental. Os casos foram identificados a partir dos contatos da pesquisadora com a rede de serviços. A proposição da pesquisa fez com que casos chegassem, num efeito de convergência: ao tomar conhecimento do tema de pesquisa os profissionais se lembravam de histórias de pessoas surdas em serviços de saúde mental vividos por colegas.

Foram utilizadas para a coleta de dados a consulta aos prontuários, a realização de entrevistas com os profissionais (gravadas e transcritas), observação do ambiente do serviço e do usuário em seu dia a dia no CAPS. Para o registro dos momentos de observação, memórias e percepçóes sobre o campo de pesquisa, foi utilizado o Diário de Campo. Atendendo as exigências da Resoluçáo CNS no 466/2012 esta pesquisa foi submetida e aprovada pelos Comitês de Ética em Pesquisa do Instituto de Psiquiatria da Universidade Federal do Rio de Janeiro/ IPUB - parecer no 2.789.491 - e da Secretaria Municipal de Saúde do Rio de Janeiro - parecer 2.604.690. Não houve financiamento para esse estudo

\section{As histórias}

\section{Quentin}

Quentin $^{6}$ é um rapaz de 30 anos de idade que chegou ao CAPS após uma internação compulsória em um hospital psiquiátrico, solicitada pelos vizinhos. Havia relatos de ele se colocar em risco e queixas de situaçóes de agressividade. 
Quentin vivia pelas ruas, morando e se alimentando por ali, raramente retornando para casa e tinha contato apenas esporádico com a mãe.

Durante a internação o CAPS foi chamado a protagonizar os cuidados a Quentin e iniciar a aproximação com sua família. A mãe ficava apreensiva com a possibilidade de Quentin ser liberado da internação, fazendo reiterados pedidos para que ele permaneça internado indefinidamente. As profissionais que o acompanhavam percebiam um comportamento bastante impulsivo e um tanto desagregado. A intérprete, que esteve nos primeiros atendimentos, relatava o quanto o discurso de Quentin era empobrecido, parecendo até mesmo um surdo que nunca tivesse aprendido Libras, apesar de ter duas familiares surdas, usuárias de língua de sinais.

Além de incentivar a ampliação da vinculação de Quentin a serviços da rede do município (clínica da família, dispositivos da Subsecretaria da Pessoa com Deficiência), a equipe pactuou, junto à Central Carioca de Intérpretes de Libras, ${ }^{7}$ a presença de intérprete para acompanhar Quentin nos atendimentos médicos e nos encontros com sua técnica de referência, uma psicóloga. Após um período inicial de vinculação, passou-se a tentar ampliar sua frequência no CAPS, para que estivesse no serviço também nas oficinas e no cotidiano do serviço. Apesar desse investimento, a equipe notou que a participação dele era irregular nesses espaços onde não havia o profissional intérprete.

Houve também a indicação que a mãe dele participasse do grupo de família do CAPS e para isso foi garantida a presença do intérprete nos grupos que acontecem quinzenalmente. Houve uma ocasião na qual a mãe compareceu e o intérprete não. A solução vislumbrada pela equipe foi utilizar o português escrito e um aplicativo ${ }^{8}$ de celular para o auxílio na comunicação, tornando possível sua participação. Entretanto, após esse episódio, ela não retornou mais ao grupo.

Atualmente, a equipe identifica uma melhora em Quentin, que apresenta sinalização mais complexa, expressando-se com mais elementos, falando de seus sentimentos e desejos. Fala ${ }^{9}$ da vontade de aprender a usar o computador e voltar a estudar, bem como do ressentimento que tem pelo fato de seu pai não lhe pagar mais pensão. Os profissionais observaram também uma relação mais carinhosa entre Quentin e a mãe. Recentemente tomaram a iniciativa de procurar um órgão da educação para solicitar para Quentin matrícula na Educação de Jovens e Adultos (EJA). Porém, Quentin ainda não está frequentando, segundo ele, pela ausência de intérprete. 


\section{Paula}

Paula tem 40 anos e faz tratamento com medicaçóes psiquiátricas na clínica da família, que teve início em decorrência de ser agressiva com a mãe em casa. Há cerca de dois anos foi encaminhada para o CAPS para ser inserida nas oficinas do serviço. Já de início, os profissionais se referiam a ela como "uma figura". Sua frequência no CAPS parece ser incerta, já que tem toda uma circulação pela comunidade, inclusive em localidades próximos ao CAPS, onde tem um bom vínculo com os comerciantes locais, com os ambulantes e com os moradores. Contam que, às vezes, é vista nas proximidades da clínica da família dizendo a todos que os carros ali estacionados são dela.

Quando os profissionais são questionados pela pesquisadora como faz isso, considerando que não fala português (é surda sinalizante), riem do estranhamento: ser comunicativa, apesar de por vezes, nada dizer em português é uma característica marcante de Paula. Contam que nas assembleias do serviço, tem sempre participaçóes enfáticas, questionadoras e reivindicativas. Apesar de não falar, fica claro, pelo modo de se expressar, o que está querendo dizer.

Anna, a profissional de referência de Paula, relata que o contato entre elas deu-se através de duas oficinas: a de pintura e a de costura. No início, Paula se apresentava agressiva e tinha dificuldade nas relações sociais: fazia menção em bater nos demais usuários e, muitas vezes, batia. Empurrava outros usuários e fazia sinais indicando que os considerava 'malucos', chegando a agredir alguns profissionais do CAPS. Segundo a mãe, em casa Paula era a mesma: tinha muita dificuldade de conviver e frequentemente era agressiva. Nessa época era dependente da máe, em especial para circular pelo bairro.

Anna conta que nunca encontrou grandes dificuldades na comunicaçáo com Paula, apesar não saber Libras. "(...) ela conversa comigo e o mais engraçado é que eu entendo", conta. Quando Paula veio para a oficina, sua chegada foi um enorme desafio, mas não sentiu necessidade de buscar recursos para se comunicar, já que Paula parecia ter seus próprios recursos.

Comunica-se com Paula utilizando gestos e o fato de estarem na oficina a materialidade dos objetos auxilia na comunicação. Por exemplo, para a escolha da cor é possível colocar as tintas na frente de Paula. Ela também utiliza a escrita para se comunicar, mesmo que em alguns momentos fique sem sentido. Nessas situaçóes, o CAPS já tentou buscar o auxílio da mãe de Paula para compreender o contexto de 
sua escrita, mas a mãe tende a desqualificar, chamando de 'maluquice' aquilo que escreve. Percebendo a disponibilidade de Anna, Paula trouxe à oficina um dicionário de Libras para mostrar sua língua à profissional que a acompanhava no serviço; desde então, leva o livro frequentemente ao CAPS. Os profissionais contam que ela demonstra muita alegria nesses dias em que leva o dicionário: anda pelo serviço com ele nas mãos mostrando os sinais para todos.

Nesse tempo em que acompanhou Paula, Anna percebeu avanços na maneira como se apresenta e se relaciona. Essa percepção do atual momento de Paula coincide com o que ouvi dos demais integrantes da equipe, mostrando-a como uma pessoa alegre e bem inserida na comunidade, sem que a comunicação ou a 'maluquice', como diria sua mãe, sejam grandes empecilhos para sua circulação.

\section{Rodolphe}

Rodolphe tem 30 anos e é morador em uma comunidade no Rio de Janeiro. É acompanhado por psiquiatra desde a adolescência em um Centro Municipal de Saúde (CMS), tendo consultas de três em três meses. Há cerca de um ano e meio foi encaminhado ao novo CAPS da área pois o profissional que o acompanhava acreditava que ele se beneficiaria de um atendimento psicossocial. Logo que chegou ao CAPS a equipe desconhecia o diagnóstico de surdez. Alguns meses após entrar no serviço, quando houve um grito muito próximo a ele, ao qual Rodolphe não emitiu resposta alguma é que a equipe desconfiou de perda auditiva e, ao questionar a mãe, descobriu que ele havia sido diagnosticado surdo aos 7 anos de idade.

Apresentou atraso no desenvolvimento desde o nascimento e a gravidez teve complicaçôes. Antes do primeiro ano de vida teve meningite, agravando ainda mais a situação. Na pré-adolescência apresentou quadro convulsivo e os primeiros episódios de automutilação e heteroagressividade, iniciando o tratamento neurológico e psiquiátrico. Nunca frequentou a escola ou teve contato com alguma língua formal escrita, falada ou sinalizada, prejudicando seu desenvolvimento. A equipe que o acompanha também se questiona sobre quais estímulos a família, com pouca orientação e pobre em recursos materiais e subjetivos, pode oferecer a ele.

A mãe de Rodolphe tem uma presença importante - e por vezes, excessiva - em sua vida. Sendo a principal responsável pelos seus cuidados, tenta suprir da melhor maneira as necessidades do filho. Um exemplo é a alimentação: tende a dar tudo o que ele quer, chegando a lhe oferecer de dois a três litros de refrigerante por dia. 
Sua comida é toda batida no liquidificador, pois segundo a mãe, ele não consegue digerir alimentos inteiros.

A principal demanda da mãe ao serviço são os episódios em que Rodolphe se torna agressivo. Esses são momentos angustiantes para a equipe, pois ele é "narrado pelas palavras da mãe," e por isso é difícil entender o que de fato se passa com ele. Por mais que tenham desenvolvido formas de comunicação entre eles, existem momentos em que a equipe se pergunta se a mãe está de fato entendendo o que Rodolphe diz. Há uma história contada pela equipe na qual o usuário estava na sala de atendimento com sua mãe, a médica e a enfermeira da equipe. Em algum momento ele faz um sinal na cabeça, semelhante a um chifre. Vendo isso, a mãe rapidamente pede à médica que termine a consulta, porque o filho quer ir embora. Curiosas sobre porque aquele sinal significa "ir embora", questionam a mãe que reponde que o filho estaria dizendo "A mulher chifruda tem que ir embora". Ainda sem entender perguntaram à mãe como ela entende isso, ao que ela respondeu: "La vêm vocês fazendo pergunta difícil!"

Durante os episódios de agitaçấo várias hipóteses foram levantadas: fome, dor, sono, medo. "Se ele está agitado está reclamando de alguma coisa... Deve ser um inferno você estar dizendo o que se passa e ninguém entender" diz Janet, profissional que o acompanha. Nesses momentos a equipe procura acalmar a mãe e evitar os excessos de medicação psiquiátrica solicitados por ela e que podem levar Rodolphe a ficar sedado, causando ainda mais obstáculo para que ele possa se expressar.

Parte importante do trabalho do CAPS foi promover pequenas separaçóes entre Rodolphe e sua mãe, como ele ficar na convivência, assembleia ou grupo de musicoterapia do CAPS acompanhado pela equipe, enquanto sua mãe participava do grupo de família ou saía do CAPS. Para tanto, era necessário que um profissional se disponibilizasse a estar com ele o tempo todo, mediando suas relaçóes e recolhendo tentativas de comunicação. Esses momentos de separação possibilitaram que a equipe construísse sua própria maneira de estabelecer trocas com ele, sem que a mãe precisasse "traduzir". Hoje ele consegue permanecer no serviço e aguardar seu retorno, quando sabe que ela não está.

Inicialmente Rodolphe suava como se estivesse com medo de estar no CAPS e permanecia o tempo todo de mãos dadas com a mãe. Com a ampliaçáo das possibilidades de comunicação com a equipe, ampliou-se também sua circulação pelo serviço. A mãe também modificou igualmente algo em sua postura passando a 
se questionar o que será de seus filhos quando morrer. Tem dito no grupo de família que percebe que os filhos dependem dela para tudo e que se preocupa com isso.

\section{Discussão}

A partir das histórias fica claro que as formas de comunicação são diversas. Sendo surdos, suas histórias compartilham da ausência de sons mas a maneira como cada um a construiu é absolutamente singular.

Na história de Quentin, a Libras aparece como um fator que marca, tanto para ele como para sua mãe, o lugar no mundo. Nele a identificação da Libras como uma língua que o faz pertencer a uma comunidade ou grupo é aparente, sendo um exemplo do que defendem os Estudos Surdos. Partimos da compreensão de que há algo da forma como as pessoas constroem sua relação com a surdez e com a linguagem que escapa às tentativas de organização e classificação, como afirmam Witchs e Lopes (2015), elas não são estanques, mas por vezes sobrepóe-se entre si.

Entretanto, é preciso destacar que é uma exigência ao CAPS (também à clínica da família e à escola) que Quentin e sua família sejam escutados em sua língua e se expressem através dela para que ocupem tais espaços. Há uma recusa de ambos a se exporem a um ambiente onde não podem se expressar em Libras, que é sua língua, como na situação em que Quentin prefere não frequentar a escola e as oficinas do CAPS ou quando sua mãe deixa de frequentar o grupo de família depois que a intérprete não comparece. Quando precisam frequentar um ambiente onde a língua que circula não é a sua, estão em um mundo estranho onde suas possibilidades de comunicação (e consequentemente de relação, expressão, territorialização) estão restritas.

Território relaciona-se com nos sentirmos “em casa”não apenas considerando um espaço geográfico, mas os signos, afetos, experiências e relaçôes que temos com determinado lugar. Assim, "a ideia de território transitaria do político para o cultural, das fronteiras entre povos aos limites do corpo e ao afeto entre as pessoas" (LIMA, YASUI, 2014, p. 597). Essa ideia ajuda a dimensionar o estranhamento de Quentin e sua mãe ao adentrarem um serviço onde náo podem se comunicar em Libras, não encontrando marcas reconhecíveis que tornam o ambiente familiar e tornam aquele lugar seu. Sob esse mesmo aspecto é possível pensar o estranhamento dos profissionais que, para receber essa família, precisam se deslocar, conhecer novos signos e abrir mão do que lhe é familiar. 
Esse território não é estanque é dinâmico e está vivo. Estamos o tempo todo inventando e construindo territórios e nos desfazendo de outros. Justamente porque conectados a afetos, relaçôes e signos que estão constantemente se transformando, nossa vinculação com o território também tende a se modificar. "Não há território sem um vetor de saída do território, e não há saída do território (...) sem, ao mesmo tempo, um esforço para se reterritorializar em outra parte" (LIMA, YASUI, 2014, p. 595).

Essas consideraçóes ajudam a pensar a relação entre linguagem e organização psíquica relatada pela equipe. No momento em que o conheceram, ele se encontrava em crise, num processo de radical de desagregação e desvinculação, a ponto de nem mesmo sua língua conseguir dar lugar a sua experiência. Sua sinalização era confusa e desarticulada, estava fora de sua "casa", do que lhe era família a ponto de a intérprete de Libras questionar-se se ele sequer conhecia a língua de sinais. Aos poucos, foi reconhecendo ao menos seu corpo como lugar de morada e de familiaridade, retomando desta forma sua língua como forma de expressão.

No caso de Paula chama a atenção desde o início o fato de que as pessoas parecem esquecer-se de que ela é surda. A coleta de dados no CAPS no qual se trata já havia se iniciado com outro caso quando os profissionais se lembraram: "Ah, tem também a Paula!". As histórias sobre ela contavam como tinha personalidade marcante e conseguia, de maneira bem clara, dizer o que queria. Os profissionais não pareciam se espantar com o fato de mesmo sendo surda, ela conseguir expressar-se claramente, mesmo que nenhum interlocutor soubesse Libras.

Enquanto Quentin relaciona-se com sua língua como um componente essencial, Paula se relaciona de maneira menos determinante com a Libras. Apesar de convidar a equipe a conhecer sua língua - quando leva o dicionário para o serviço - a ausência da Libras não oferece barreiras para que se comunique. Nesse sentido, tanto ideia de surdez enquanto falta de audição quanto a ideia de surdez enquanto cultura parecem incompletas para dizer a maneira como ela se relaciona com sua língua. Paula desenvolveu uma forma para se comunicar que é singular, única e encontrou escuta em diversos lugares, possibilitando-lhe transitar. A história de Paula demonstra como encontrar espaços acessíveis, ou seja, em que exista a possibilidade de adaptarse às suas diversas formas de comunicar, possibilitam acesso e nesse sentido, nos aproxima das propostas do Modelo Social da deficiência.

Rodolphe tem suas possibilidades de comunicação bastante restritas, tendo apenas alguns sinais caseiros criados na relação com sua mãe. Rodolphe é frequentemente 
narrado e interpretado por aqueles ao seu redor, tendo poucas possibilidades de interferência nesse processo, a menos que esteja diante de um interlocutor atento. A história na qual ele faz um sinal e sua mãe rapidamente o interpreta como "mulher chifruda" demonstra o quanto é necessário um tempo maior para que os sentidos de seu comunicar sejam construídos com o interlocutor.

Strobel (2016) falando sobre o desenvolvimento linguístico da pessoa surda, destaca que desde a tenra infância as informaçóes não chegam para um bebê surdo da mesma maneira que chegam para o ouvinte, caso os pais da criança surda não forem usuários de Libras. Seu mundo se constitui de maneira diferente de uma criança ouvinte, possivelmente com um repertório mais restrito caso as pessoas que estão em seu entorno não se ocupem de tornar as informaçóes acessíveis a ela.

Portanto, com poucos recursos linguísticos e subjetivos, Rodolphe precisa se haver em um mundo onde ele é falado por outros, um mundo em que dizem sobre ele e seu modo de existir através de palavras sobre as quais ele não tem domínio. Nem mesmo o sinal que faz de chifre pode ganhar sentido no encontro com a equipe, sendo rapidamente colocado nas palavras da mãe. Seu interlocutor necessita dar tempo para que a comunicação aconteça e estar atento as múltiplas formas de dizer. Janet, conta histórias de sua experiência em trabalhos anteriores e como aprendeu a ouvir palavra onde há silêncio, grito, agitação e apesar de, na maioria das vezes, não conseguir distinguir o que dizem (É fome? É medo? É dor?), mantem-se atenta a essas formas de dizer. Portanto, assim como Paula, Rodolphe pode comunicar-se com a equipe a partir do momento em que ela reconheceu suas formas de dizer.

A partir da chegada dessas pessoas nos serviços de saúde mental, os profissionais depararam-se com um sentimento de despreparo e com a necessidade de inventar formas de trocar com o usuário (...) isto é algo que ainda precisamos avançar, a gente ainda está engatinhando no caso do Rodolphe. A gente tem precisado se reinventar a cada vez", diz Kristy outra profissional que o acompanha no CAPS. Apesar da sensação de que pouco se sabe ou se produziu, a possibilidade de se reinventar também abre espaço para surgir o novo, para "uma clínica comprometida com a construçáo e a produçáo de uma subjetividade aberta à alteridade; uma clínica sempre atenta àquilo que propicia a criação e potencializa os processos de transformação do cotidiano" (LIMA, 2004, p. 78).

Nos CAPS, com serviços essencialmente territoriais, parte fundamental do trabalho é a permeabilidade ao território e às subjetividades que ali habitam. Como 
propõe Amarante (2007), convém pensar o campo da Saúde Mental "não como um modelo ou sistema fechado, mas sim como um processo", (p. 63) no sentido de algo que está constantemente sendo reconstruído e redesenhado, de acordo com diferentes atores envolvidos. Isso significa ser condição para o trabalho no CAPS que a cultura (e consequentemente a língua) dos seus usuários seja parte da construção. Por isso, a chegada de usuários surdos ao CAPS causou também transformaçóes nos serviços, que se reconfiguraram e reinventaram para fazer caber modos de existir e comunicar.

Regan e Evelyn, profissionais que acompanham Quentin, disseram da dificuldade em receber essa família e do processo de deslocamento pelo qual passaram: “(...) foi difícil pra equipe, no início foi muito difícil. (...) Né dessa dificuldade que a gente passou e acaba que eles passam também. Porque a equipe ficava insegura de como receber" (Regan). Sentiram-se provocadas pela língua e pelo mundo de Quentin, o da surdez e buscaram intersecçóes e encontros entre esses dois mundos: "Aí eu já saí daí (primeiro grupo de família com participação da mãe de Quentin) dizendo que eu tinha que aprender Libras (...) Então eu comecei (curso de Libras), tô engatinhando aí” (Evelyn). Outra marca dessa intersecção foi o "batismo" de Regan quando, ganhou um sinal ${ }^{10}$ de Quentin. Essa marca diz que na cultura surda, ela agora tem um nome, tem um lugar; é também território dela.

Se por um lado, Evelyn e Regan sentiram-se convocadas a aprender Libras e garantir os atendimentos com intérprete para Quentin e sua mãe, sempre que possível, na história de Paula diversos fatores possibilitam o acesso ao serviço, mesmo que o atendimento em Libras não seja oferecido. Além de fatores pessoais (como uma personalidade expansiva), o fato de ela ter tido acesso à educação e conhecer a Libras, Paula encontrou nos espaços (a rua, o estacionamento em frente à clínica da família, o CAPS, o comércio local) a possibilidade de ser escutada, mesmo que não "diga" da forma mais convencional. Nesse sentido, sua presença no serviço exige que os profissionais estejam abertos a comunicar-se não através de uma língua formal, mas através dos elementos que Paula aprendeu a utilizar ao longo da vida: a escrita, imagens no computador e os materiais presentes nas oficinas tornam-se possibilidades de se comunicar com ela.

Isso não significa, que o atendimento em Libras não seria benéfico para Paula, mas significa que não foi uma condição para que fosse cuidada no CAPS. O desafio que Paula apresenta é que as possibilidades de comunicação sejam diversas, e reconhecidas múltiplas formas de dizer como oportunidade de trabalho e de 
escuta. Suas produçôes nas oficinas, sua circulação pelo comércio, suas falas nas assembleias, as imagens no computador, os objetos. Paula transforma todas elas em forma de dizer e comunicar e foi necessário que os profissionais estivessem ali como interlocutores para reconhecer o que dizia Paula, em suas múltiplas formas.

Os profissionais são convocados a fazer um exercício para reconhecer a demanda, mesmo que não venha da forma habitual. Estar atento aos modos como cada pessoa se comunica (palavras, gestos, sons, expressōes, choro) torna-se ponto chave para o acesso ao serviço. Esse aspecto aparece fortemente na história de Rodolphe.

Janet relata a dificuldade que a equipe tem em estar com Rodolphe nos espaços coletivos do CAPS “...teve algumas vezes que a gente conseguiu que ele participasse da Oficina do Corpo ou então ele consegue ficar na assembleia porque tem alguém fazendo massagem nas costas, nos pés...fazendo um dengo com ele (risos). (...) aquilo pode até ser terapêutico, mas isso...é nosso papel? Assim de ele estar na assembleia discutindo coisas do serviço e a gente estar...fazendo massagem?”.

Janet evidencia o quanto é necessário a presença junto a Rodolphe para que ele consiga ocupar os espaços e estabelecer trocas. A presença do profissional junto a ele permite que esteja em espaços onde não se esperaria sua participaçáo, como a assembleia. A exigência que Rodolphe faz para que possa se comunicar é, portanto, uma disponibilidade de presença e de corpo por parte dos profissionais, criando novas formas de habitar espaços que são comumente dominados pela palavra falada. Esse jeito de estar junto com uma presença constante não é algo simples de ser compreendido e executado pela equipe do CAPS, como relata Janet. Na compreensão de alguns profissionais há algo na maneira como Rodolphe se relaciona que faz com que a equipe questione se faz sentido imprimir esforços para ajudá-lo a estar na assembleia. Apesar dessa dificuldade e dos questionamentos, a equipe - mesmo que uma parte dela -, emprega energia para que isso aconteça.

Os questionamentos da equipe, apontam para a importância da existência de serviços nos quais as possibilidades de cuidado não se encerram em si mesmas, não se fecham no que já está dado. A pergunta (“mas isso é nosso papel?”) apresentada por Janet aponta para o processo de elaboração de uma resposta. $\mathrm{O}$ encontro desta equipe com a maneira de Rodolphe estar no mundo gerou uma pergunta que pode fazer as concepçôes dos serviços se reconfigurarem. Isso é uma forma de comunicar, já que Rodolphe conseguiu provocar e convocar seu interlocutor. Assim, Rodolphe 
exige da equipe, além de presença, que suas formas de se apresentar e ocupar os espaços possam também ser lidas como uma tentativa de comunicar-se.

As reconfigurações e reinvençôes, não são no entanto, processos simples. Ao longo da pesquisa ouviu-se inúmeras vezes dos profissionais a importância e inexistência de espaços de formação que discutam questôes relacionadas à surdez com profissionais de saúde. Os relatos no geral são de que a questão da surdez nunca havia sido pensada pelos profissionais como um problema. Somente ao terem contato com ela é que puderam se dar conta das singularidades de se receber uma pessoa surda. Esse pedido coincide com o que traz Barbosa et al (2003) com relação às necessidades que os profissionais de saúde apontam quando recebem pessoas surdas. Está claro que existe uma grande demanda por formação nesse sentido.

\section{Considerações Finais}

Oferecer cuidado é sempre tarefa complexa, pois exige do profissional associar a demanda de quem chega e o que pode ser oferecido pelo serviço de saúde, em um universo de linguagens. Quando se trata de uma pessoa surda torna-se necessário que o profissional de saúde esteja ainda mais atento à variável linguagem a fim de que perceba as sutilezas das possibilidades e preferencias linguísticas de cada pessoa.

Quentin, Paula e Rodolphe são três pessoas surdas com demandas de cuidado em saúde mental mas apresentam formas distintas de se comunicar e estabelecer trocas: Quentin necessita que seja oferecido atendimento em sua língua, Paula que o serviço ofereça múltiplas e variadas formas de comunicar-se, enquanto Rodolphe necessita presença e que sua maneira de estar nos espaços possa ser entendida como forma de comunicação. $\mathrm{Na}$ medida em que o seu interlocutor, o profissional de saúde, apresenta-se disponível para comunicar-se à maneira do usuário, produz-se acesso e cuidado.

As histórias demonstram que a chegada de pessoas surdas em um serviço aberto e permeável como o CAPS possibilitou a criação de formas de comunicarse que estão para além do falar e escutar, partindo da necessidade de cada um desses sujeitos. É no fazer cotidiano, com cada usuário do serviço que propostas de cuidado náo homogeneizantes ganham vida e para tanto é preciso que se incluam as singulares formas de se comunicar, não só daqueles que não falam o português oral, mas considerando os efeitos que a língua tem sobre constituição subjetiva de 
cada um. Assim, o profissional de saúde estar atento à forma como os usuários do serviço se comunicam pode ser de grande valia não somente para os usuários surdos, mas para todos.

Não é simples, entretanto, o trabalho que os profissionais necessitam fazer para reinventar-se a partir de cada um que chega nos serviços de saúde. Nesse sentido, tornam-se fundamentais os espaços de informação e formação continuada para a construção de práticas de cuidado comprometidas com a singularidade do usuário surdo no serviço de saúde.

\section{Referências}

AMARANTE, P. Saúde Mental e Atenção Psicossocial. Rio de Janeiro: Editora Fiocruz, 2007, $3^{\mathrm{a}}$ ed, 120p.

BARBOSA, M. A, et al. A Língua Brasileira de Sinais - Um desafio para a assistência de enfermagem. Revista de Enfermagem da UERJ, Rio de Janeiro, v. 7, n. 3, p. 247-251, 2003.

BRASIL. Ministério da Saúde. Secretaria Nacional de Assistência à Saúde. $A B C$ do SUS: Doutrinas e Princípios. Brasília/DF.1990

CARdosO, A. H. A.; RODRIGUES, K. G.; BACHION, M. M. Perception of persons with severe or profound deafness about the communication process during health care. Rev. LatinoAm. Enfermagem, Ribeirão Preto, v. 14, n. 4, p. 553-560, Aug. 2006.

CHAVEIRO N.; BARBOSA, M. A. Assistência ao surdo na área de saúde como fator de inclusão social. Rev Esc Enferm USP, v.39, n.4, p. 417-22, 2005.

CHAVEIRO N.; BARBOSA, M. A.; PORTO, C. C. Revisão de literatura sobre o atendimento ao paciente surdo pelos profissionais da Saúde. Rev Esc Enferm USP, v. 42. n. 3, p. 578-83, 2008.

CHAVEIRO N.; BARBOSA, M. A.; PORTO, C. C.; MUNARI, D. B.; MEDEIROS, M.; DUARTE, S. B. R. Atendimento à pessoa surda que utiliza a língua de sinais - na perspectiva do profissional da saúde. Cogitare Enfermagem, UFPR, v. 15, n. 4, p. 639-45, out./dez. 2010.

COSTA, S. M. Inclusão no curso médico: Atenção Integral à Saúde das Pessoas com Deficiência. Rio de Janeiro: HP Comunicação Editora, 2015, 278 p.

COSTA et al. $\mathrm{O}$ atendimento em saúde através do olhar da pessoa surda: avaliação e propostas. Rev Bras Clin Med. 2009; v.7, n.3, p.166-170, 2009

FOUCAULT, M. Vigiar e Punir: nascimento da prisão. Petrópolis: Vozes, 2014, 42º ed, 302 p.

FRANÇA, E. G. et al . Dificuldades de profissionais na atenção à saúde da pessoa com surdez severa. Cienc. enferm., Concepción, v. 22, n. 3, p. 107-116, sept. 2016. 
LIMA, E. M. F. A. Oficinas, Laboratórios, Ateliês, Grupos de Atividades: Dispositivos para uma clínica atravessada pela criação. In: COSTA, C. M. e FIGUEIREDO, A. C. Oficinas terapêuticas em saúde mental - sujeito, produção e cidadania. Coleçôes IPUB. Rio de Janeiro, Contra Capa Livraria, 2004, p. 59 - 81.

LIMA, E. M. F. A.; YASUI. Territórios e sentidos: espaço, cultura, subjetividade e cuidado na atenção psicossocial. Saúde debate, Rio de Janeiro, v. 38, n. 102, p. 593-606, Set. 2014.

LOPES, R. M., VIANNA, N. G, SILVA, E. M. Comunicação do surdo com profissionais de saúde na busca da integralidade. Saúde e Pesquisa, v. 10, n. 2, p. 213 - 221, mai-ago 2017.

MARTINS, F. C. Discursos e Experiências de sujeitos surdos sobre audismo, deaf gain e surdismo. 2013. Dissertação (Mestrado em Educação) - Faculdade de Educação, Universidade Federal de Pelotas, Rio Grande do Sul.

MASCARENHAS, L. T. Deficiência e surdez em análise: desafios do "estar com". In MASCARENHAS, L. T. Encontros Entre Surdos e Ouvintes na Escola Regular - Desafiando Fronteiras, Rio de Janeiro: EdUFF, 2016, 170p.

MELLO, A. G. (s/d). Especificidades da violência contra a pessoa com deficiência auditiva. Textos de apoio do Programa estadual de prevençáo e combate à violência contra pessoas com deficiência do Governo do Estado de Sáo Paulo.

MELLO, A. G, NUERNBERG, A. H. Gênero e deficiência: interseçóes e perspectivas. Estudos Feministas, Florianópolis, v. 20, n. 3, p. 384, setembro-dezembro, 2012.

MINAYO, M. C. S et al . Pesquisa social: teoria, método e criatividade. 21. ed. rev. atual. Petrópolis: Vozes, 2002, 80p.

OLIVEIRA, Y. C. A; CELINO, S. D. M, COSTA, G. M. Comunicação como ferramenta essencial para assistência à saúde dos surdos. Physis, Rio de Janeiro, v. 25, n. 1, p. 307-320, Mar. 2015.

SANTOS, E. M; SHIRATORI, K. As necessidades de saúde no mundo do silêncio: um diálogo com os surdos. Revista Eletrônica de Enfermagem, v. 06, n. 01, p.68-76, 2004.

STROBEL, K. As imagens do outro sobre a cultura surda. Florianópolis: Ed da UFSC, 2016, 4. ed.

TEDESCO, J. R.; JUNGES, J. R. Desafios da prática do acolhimento de surdos na atenção primária. Cad. Saúde Pública, Rio de Janeiro, v. 29, n. 8, p. 1685-1689, Aug. 2013.

TORRES, E. F.,MAZZONI, A. A., MELLO, A. G. Nem toda pessoa cega lê em Braille nem toda pessoa surda se comunica em língua de sinais. Educação e Pesquisa, São Paulo, v. 33, n. 2, p. 369-385, maio/ago. 2007.

WITCHS, P. H., LOPES, M. C. Surdez como matriz de experiência. Revista Espaço, Rio de Janeiro, n 43, p.32 - 49, jan-jun, 2015.

YIN, R. K. Estudo de Caso - Planejamento e Métodos. Tradução por Daniel Grassi. Porto Alegre: Bookman, 2001, 2a ed, 205 p. 


\section{Notas}

${ }^{1}$ A Biblioteca Virtual em Saúde, através dos Descritores em Ciências da Saúde (DeCS) apresenta acesso como o conceito que se preocupa com todos os aspectos da qualidade, acessibilidade e avaliação de cuidados de saúde e entrega de cuidados de saúde enquanto acessibilidade refere-se à possibilidade dos indivíduos adentrarem e utilizarem os serviços de atenção à saúde, com vistas à resoluçẫo de problemas que afetem a saúde. Assim, nesse estudo, acessibilidade refere-se a recursos utilizados para garantir a comunicaçáo enquanto acesso, relaciona-se a chegada do usuário ao serviço, não apenas fisicamente, mas a possibilidade de elaborar uma demanda ao serviço, mesmo que não através do português oral ou escrito ou mesmo através de uma língua formal

${ }^{2}$ Normalização é o processo que "compara, diferencia, hierarquiza, homogeiniza, exclui" a partir das instituiçóes disciplinares e seus instrumentos de controle (Foucault 2014, p 180).

${ }^{3}$ Campo interdisciplinar do saber que propõe a cultura como não homogênea e investiga a multiplicidade cultural, as relaçôes entre culturas e o quanto essas relaçôes envolvem poder. Alguns dos autores utilizados pelos Estudos Surdos são Stuart Hall, Gayatri Spivak e Homi Bhabha.

${ }^{4}$ Sistema linguístico de natureza viso-espacial, com estrutura gramatical própria. Reconhecida como segunda língua oficial do Brasil desde 2002, através da Lei 10.436.

${ }^{5}$ Os nomes utilizados são fictícios e foram inspirados em filmes que tem como tema a surdez: "Um Lugar Silencioso" (2018) com direção de John Krasinski, "The Hammer” (2010) com a direção de Oren Kaplan e "A Gangue" (2014) do diretor Myroslav Slaboshpytskyi

${ }^{6}$ Quentin tem surdez neurosensorial por causa genética (Síndrome de Waardenburg)

${ }^{7}$ Grupo de profissionais intérpretes que acompanha surdos em atendimentos de ordem jurídica, trabalhistas, de saúde, entre outras (Dados do site da Prefeitura do Rio de Janeiro: http://www.rio.rj.gov.br/web/ smpd/exibeconteudo?id=2809652)

${ }^{8}$ Aplicativo Hand Talk, criado em 2012. É gratuito e conta com uma animação chamada Hugo que faz a tradução automática do conteúdo escrito.

${ }^{9} \mathrm{Na}$ pesquisa termos como "fala" ou "palavra" aparecem referindo-se a diversas formas de comunicação. Optou-se por manter esse uso ampliado dos termos mesmo em situaçóes nas quais não se referia à fala ou palavra no sentido estrito para chamar a atenção ao fato de que os sentidos atribuídos à comunicação na situação na qual se dá, não são estanques, assumindo sentidos a depender de como o interlocutor a recebe. ${ }^{10}$ Pessoas nas comunidades surdas são conhecidas além de seus nomes, por sinais. A partir de características físicas ou de personalidade marcantes, a pessoa é batizada com um sinal. 


\section{Abstract}

\section{Communication singularities in the meeting between deaf people and mental health professionals}

Part of the struggles of people with disabilities and their movements has been, not only the recognition of human diversity but the understanding that people with the same disability, like deafness, are not a homogeneous group. Health professionals, when facing that diversity, generally feel unprepared and with insufficient knowledge. The objective of this study is to present different forms of communication that may happen when deaf subjects meet these professionals in mental health services, using Multiple Case Study. The results point to diversity in ways of communicating, calling the professionals to create new forms of work and care in the meeting with users in mental health services. It is in the daily work, with every different service user, that suggestions of care which take diversity into account, gain life. And for that, it is also important to include diversity in the way of communicating. The creation of unique forms of communication demanded of health professionals is only possible with the support of informational spaces and continuing education.

> Keywords: Access, diversity, deafness, mental health. 